\title{
Erratum to: Investigation of the atmospheric mesoscale circulation patterns and their simulation with WRF-CHEM model of the dust storm occurrence over the southern coast of the Caspian Sea
}

\author{
Sammaneh Negah $^{1}$ - Amir Hussain Meshkatee ${ }^{1}$ - Sohrab Hajjam ${ }^{1}$ - Ali Kamali ${ }^{1}$
}

Published online: 3 November 2016

(C) Saudi Society for Geosciences 2016

Erratum to: Arab J Geosci

DOI 10.1007/s12517-016-2670-9

The original version of this article, unfortunately, contained error.

Author "Amir Hussain Meshkatee" family name was misspelled. Given in this article is the correct family name.

The online version of the original article can be found at http:// dx.doi.org/10.1007/s12517-016-2670-9.

Amir Hussain Meshkatee ameshkatee@yahoo.com

1 Department of Meteorology, Science and Research Branch, Islamic Azad University, Tehran 4479644231, Islamic Republic of Iran 